\title{
Androgen expression \& clinicopathological features in male breast cancer
}

Lia P Rebaza1, Carlos A Castaneda*,2,3, Miluska Castillo², Luis A Bernabe², Joselyn Management Sanchez ${ }^{2}$, Gabriela Calderon1, Jorge Dunstan1, Miguel de la Cruz , Jose M Cotrina1, Julio Abugattas ${ }^{1}$, Henry Guerra4 ${ }^{4}$ Maria R Villa-Robles ${ }^{4}$, Nathaly Poma ${ }^{5}$, Omar Mejia ${ }^{2}$ \& Henry L Gomez

${ }^{1}$ Department of Breast Surgery, Instituto Nacional de Enfermedades Neoplasicas, Lima 15038, Lima, Peru

${ }^{2}$ Research Department, Instituto Nacional de Enfermedades Neoplasicas, Lima 15038, Lima, Peru

${ }^{3}$ Faculty of Medicine, Universidad Peruana San Juan Bautista, Lima 15067, Lima, Peru

${ }^{4}$ Pathology Department, Instituto Nacional de Enfermedades Neoplasicas, Lima 15038, Lima, Peru

${ }^{5}$ Medical Oncology Department, Instituto Nacional de Enfermedades Neoplasicas, Lima 15038, Lima, Peru

*Author for correspondence: Tel.: +511 992157 220; Fax: + 511620 4991; carloscastanedaaltamirano@yahoo.com

Aim: To investigate prognostic features in male breast cancer (MBC). Methods: Clinicopathological information from $40 \mathrm{MBC}$ patients was retrospectively reviewed. Androgen receptor (AR) and estrogen receptor (ER) were prospectively stained out in 22 cases and counted through software program analysis. Results: Median age was 65.5 years; most cases were Stage II (40\%), Grade II (37.5\%), ER $\geq 10 \%(72.5 \%)$ and $\mathrm{PgR} \geq 10 \%$ (75\%). AR $>10 \%$ was found in 17 of 22 cases. Although AR expression was correlated with ER, there are some cells without coexpression. Axillary node involvement was associated with DFS $(p=0.001)$ and age $(p=0.002)$ was associated with overall survival. Conclusion: ER is expressed in most $\mathrm{MBC}$ cases and is correlated with AR. Axillary involvement and age were associated with survival.

\section{Graphical abstract:}

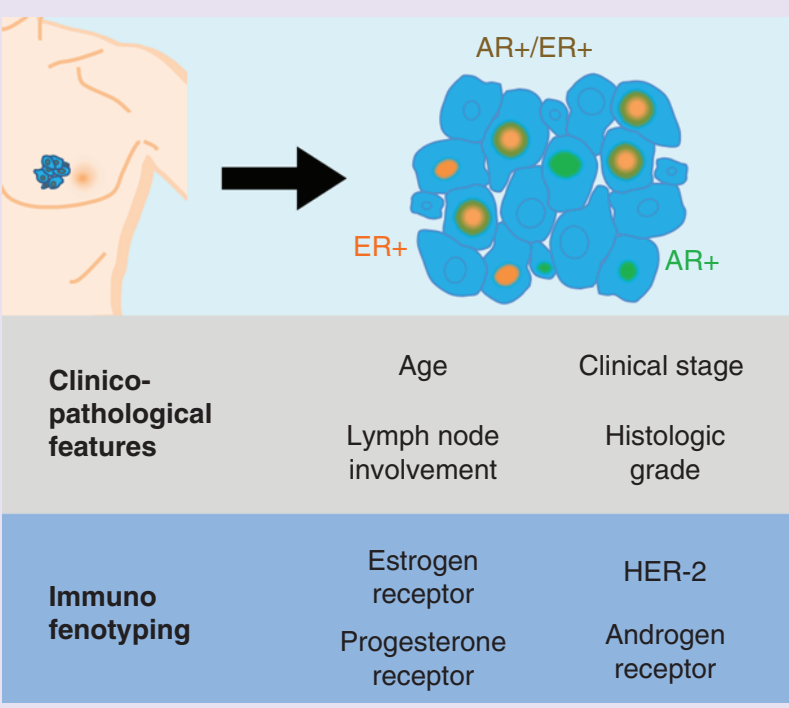

First draft submitted: 30 November 2017; Accepted for publication: 11 April 2018; Published online: 7 June 2018

Keywords: androgen receptor $\bullet$ breast cancer $\bullet$ estrogen receptor $\bullet$ immunohistochemistry $\bullet$ lymphocytes $\bullet$ male 


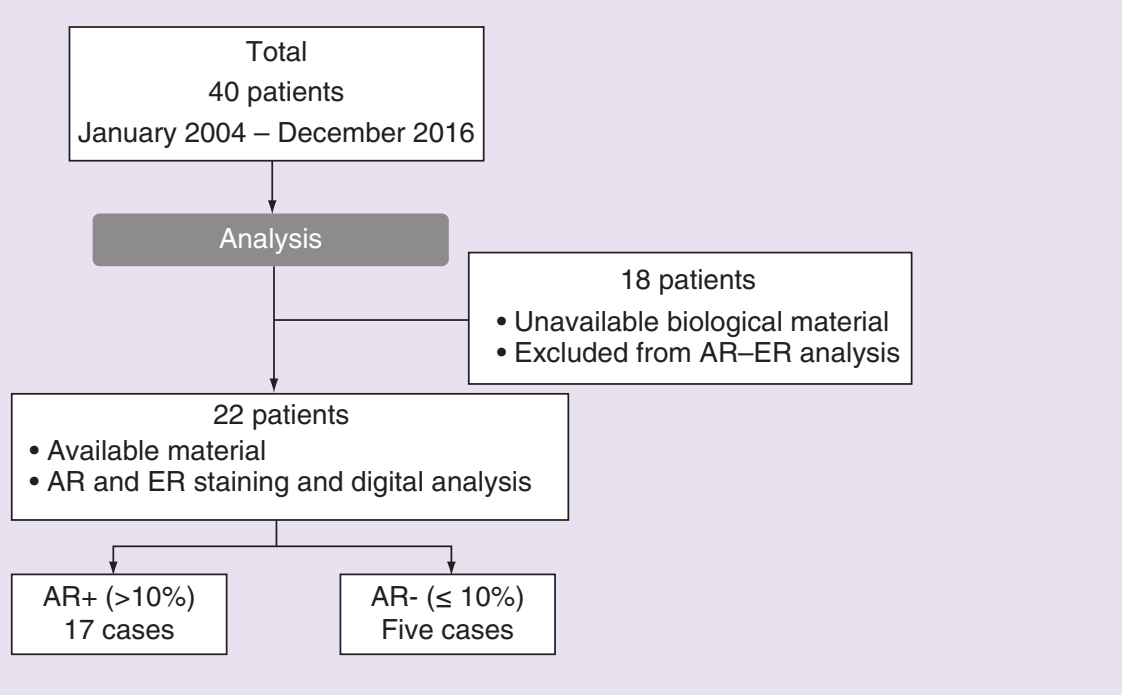

Figure 1. Diagram of selected population of male breast cancer.

Male breast cancer $(\mathrm{MBC})$ is a rare disease, which accounts for less than $1 \%$ of all instances of cancer in men and accounts for only $0.7 \%$ of all breast cancer diagnoses [1]. Breast cancer happening in males differs to women in age at diagnosis, prevalence of histological types, estrogen receptor (ER) positive rates and prognosis [2].

Androgen receptor (AR) is a member of the nuclear steroid receptor subfamily with functional and structural similarity to ER and engaged with regulation of cell proliferation [3-5]. Increased risk of breast cancer is seen in patients with hypoandrogenism, and androgens exert anti-mitogenic effects in breast cancer cell lines and cause regression of breast tumors in rats [6,7]. Most authors report AR expression in 60-80\%, a positive correlation with ER, an association with better outcome and a prediction of response to anti-androgen or anti-estrogen treatment in female breast cancer cases [8,9]. Some series suggest that AR expression has higher rates and could show similar prognostic and predictive features in male breast cancer [10-15]. However, a series of South American MBCs are scarce and more information is needed about the impact of $\mathrm{AR}$ expression over $\mathrm{MBC}$ behavior because the extensive experience using androgen pathway modulation in males with prostate cancer [16].

We analyze clinicopathological features of $40 \mathrm{MBCs}$ from a Peruvian retrospective series in order to look for prognostic factors, as well as ER and AR expression in the prospective subgroup of 22 cases in order to evaluate their correlation (Figure 1).

\section{Patients \& methods}

\section{Patients}

A search for breast cancer happening in males who came to the Institute Nacional de Enfermedades Neoplasicas from January 2004 to December 2016 was performed through the electronic archive system (Figure 1). Clinical charts were reviewed to obtain follow-up information. Archived H-E stain slides were reviewed by an Institute Pathologist (J Sanchez) to complete pathological features including histologic grade in accordance with the modified Scarff-Bloom-Richardson system and tumor-infiltrating lymphocytes in accordance with international recommendation $[17,18]$.

\section{Immunohistochemistry}

Tissue sections of $4 \mathrm{~mm}$ thickness were cut from the tissue paraffin blocks, and immunohistochemical staining for $\mathrm{AR}$ and ER was carried out according to the manufacturer's instructions. Briefly, sections were transferred onto adhesive slides and were dried at $60^{\circ} \mathrm{C}$ for $30 \mathrm{~min}$. After incubation with the primary antibodies, immunodetection was performed using biotinylated anti-mouse immunoglobulin, followed by peroxidase-labeled streptavidin. The labeled streptavidin biotin kit was used, and 3,3'-diaminobenzidine chromogen was used as a substrate. Phosphatebuffered saline was used to replace the primary antibody and served as the negative control. Staining for evaluating 


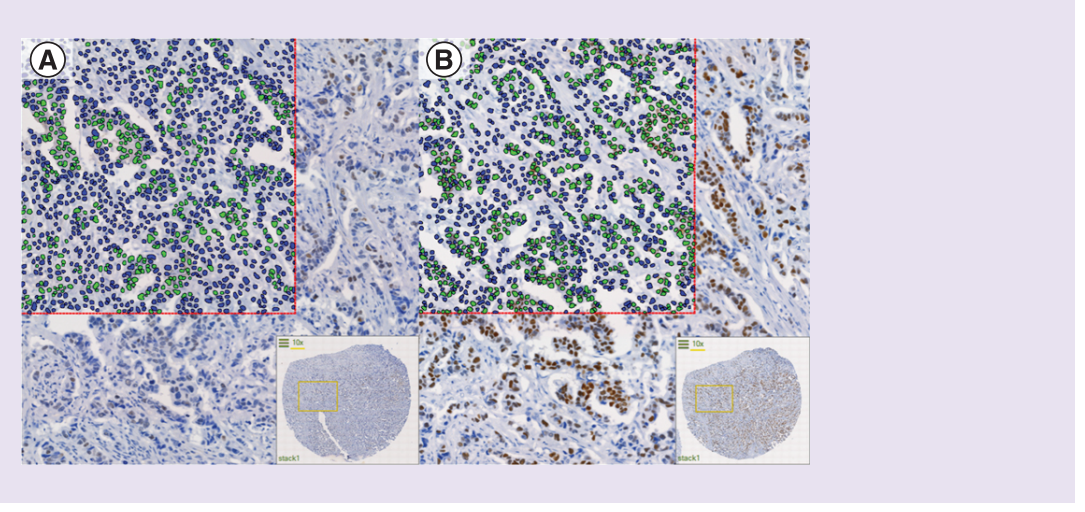

Figure 2. Comparison of biomarkers in the same tumor areas. Positive status of androgen receptor (A) and estrogen receptor (B) indicated by the green label in nuclear structures.

AR expression used monoclonal mouse anti-human AR antibody (Dako AR441, Glostrup, Denmark) and ER expression used monoclonal rabbit anti-human ER antibody (Zhongshan Bio., Beijing, PR China). Normal prostatic tissue (pathology archive) was used as positive control of AR. The sections were observed under a light microscope $(\times 100$ to $\times 400)$.

Two Institute pathologists performed the lecture of pathology slides (H Guerra and J Sanchez). Pathology criteria for AR positivity were based on the intensity (negative, weak, moderate or strong) and percentage of tumor cells showing expression through pathology eyeball methodology. Tumors that had more than $10 \%$ of cells exhibiting a moderate or strong intensity of AR expression were considered positive (similar to previous reports) [10]. Regarding ER, we followed ASCO/USCAP guidelines and positive status was accepted as $\geq 1 \%$ [19].

Additionally, slides of AR and ER staining were scanned in BX63 Olympus (Tokyo, Japan) using the $\times 40$ objective lens and the analysis was performed through Visiopharm software in 19 BCM cases. Hot spots were selected (area with a higher density of positive-staining cells) under a low-power field $(100 \times)$. The counting process was performed in five independent areas under a high-power field $(400 \times)$. AR and ER immune-positivity were evaluated in the same nuclear stain areas. Negative and positive cells were marked in blue and green by TissueMorph-Visopharm Software, Hoerlson, Denmark. Both rates of AR and ER were obtained through the ratio between median number of positive over all cells (M Castillo and LA Bernabe) (Figure 2). The process was supervised by an Institute pathologist (J Sanchez).

\section{Statistical analysis}

Associations of clinicopathological variables were performed by Chi-square test of independence or Fisher's exact test. Association with survival was initially analyzed using the Kaplan-Meier. Differences between categories were tested by the log-rank or Breslow (generalized Wilcoxon) tests according to the case. Cox regression analysis was used to adjust for other prognostic indicators. Overall survival (OS) was calculated from the date of diagnosis until death or until the last follow-up whether the patient was alive. Disease-free-survival (DFS) was calculated from the date of diagnosis until relapse or the date patients were last known to be alive. Identification of co-expression of $\mathrm{AR}$ and ER in the same cells was performed by linear correlation coefficient and variability of numeric variables through Pearson correlation test and deviation standard measure, respectively. A p $<0.05$ was considered significant. Analyses were performed using the SPSS statistical package (IBM SPSS Statistical 19).

\section{Results}

\section{Clinicopathological features in the whole series}

Patients under observation were 40 men. Median age at the time of diagnosis was 65.5 years (24-90 years). Two (5\%) cases were Stage I, 16 (40\%) Stage II, 14 (35\%) Stage III, four (10\%) Stage IV, and the stage was unknown in four (10\%) cases. Tumor size was evaluated in 31 cases and had a median of $4 \mathrm{~cm}$ (maximum of $18 \mathrm{~cm}$ ). Skin involvement (pT4) was observed in 13 cases (32.5\%). 19 cases (47.5\%) had clinical lymph node involvement. Most cases were invasive ductal carcinoma NST (82.5\%). Histological grade was evaluated in 27 tumors, and most frequent were Grades I (17.5\%) and II (35\%). Hormone receptor was evaluated in 35 cases, and ER-negative was 


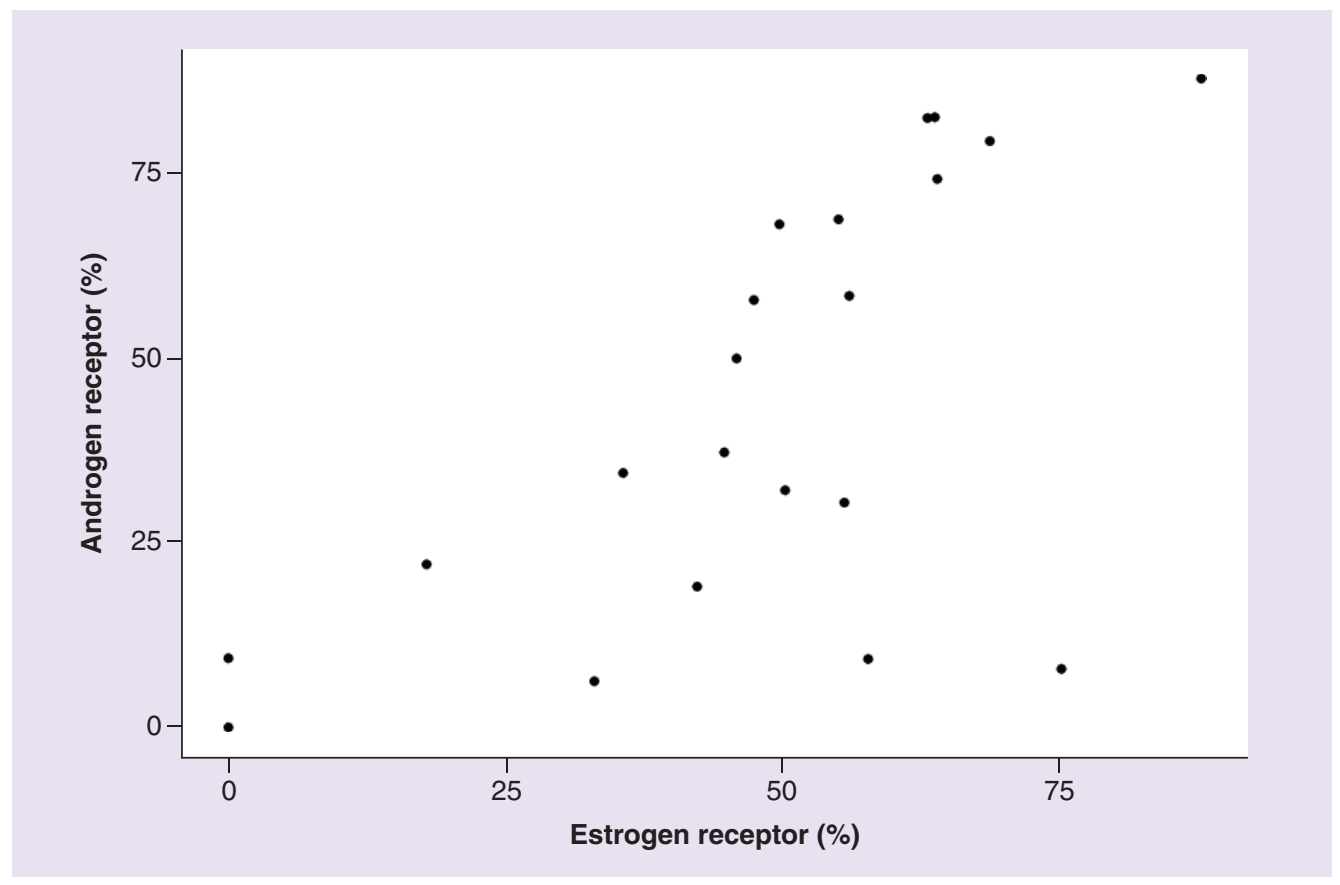

Figure 3. Correlation between estrogen receptor and androgen receptor in 22 male breast cancer patients analyzed through digital analysis $(p=0.008)$.

found in six cases, $1-9 \%$ in one case, $\mathrm{ER} \geq 10 \%$ in 29 (72.5\%), and $\operatorname{PgR}(\geq 10 \%)$ in 30 (75\%). Only one patient was HER2 ${ }^{+++}, 30$ patients $(75 \%)$ were HER2 ${ }^{-}$and four patients $(10 \%)$ were HER2 ${ }^{++}$(however, FISH/ ISH HER2 were not performed). Mastectomy was performed in 28 (70\%), tumorectomy in four (10\%), axillary dissection in $29(72.5 \%)$, and sentinel lymph node biopsy in two (5\%) cases. Adjuvant chemotherapy was administered to nine of the 16 Stage II patients and four of the 14 Stage III patients. Chemotherapy was administered to three of the 4 Stage-IV patients. Hormone therapy was administered only to cases with ER-positive status if patient fulfill treatment criteria (Table 1).

\section{Prospective evaluation of androgen receptor}

Androgen receptors (AR) were evaluated by eyeball pathology methodology in 22 cases (Figure 1) and median percentage of cells with AR expression was 45\%. There were five cases with AR-negative (22.7\%) (including two cases from one up to $10 \%)$ and 17 AR-positive (>10\%) cases (77.3\%). Under this classification, AR-positive is associated with low clinical tumor size $(\mathrm{p}=0.032)$, ER-positive status $(\mathrm{p}=0.043)$ and PgR-positive status $(\mathrm{p}=0.043)($ Table 2$)$.

The relationship between androgen \& estrogen receptor expression in same HPF

Evaluation of the same 5HPF for AR and ER found that, 510 cells (34.45\%) (range 92-1221) from 1480 cells (range 774-2377) were positive for AR, and 734 cells (50.3\%) (range 261-1098) from 1459 (range 859-2481) were positive for ER. Variability among the 5HPF for every case was higher for AR than ER (SD 0.302 vs 0.238 ). Variables AR and ER had a correlation coefficient index of $0.682(\mathrm{p}=0.008)$ through Pearson test. However, the correlation was poor for three cases (two cases were clinical Stage II and one case was clinical Stage III) (Figure 3).

\section{Prognostic clinicopathological factors}

The median follow-up was 2.94 years. Longer DFS was associated with the absence of positive lymph nodes $(p=0.001)$. Longer OS was associated with younger age $(p=0.002)$ and right-side tumor cancer location $(\mathrm{p}=0.036)$ in the whole series (Figure 4). Multivariate survival analysis performed by Cox regression found that, the age at diagnosis $(\mathrm{p}=0.011, \mathrm{HR}=1.067,95 \%(\mathrm{HR})=1.015-1.122)$ was associated with high OS, and lymph nodes involvement ([1-9] axillary lymph nodes vs $\geq 10$ lymph nodes, $\mathrm{p}=0.042$ ) and (negative axillary lymph nodes 
Table 1. Prognostic value of clinical-pathological features $(n=40)$.

Features

Sub-classification

Total

\begin{tabular}{|l|l|}
\hline Age & \\
\hline & Median (range) \\
\hline & $<70 y$ \\
\hline & $>70 y$ \\
\hline
\end{tabular}

$n=40(\%)$

OS at 5 years $=51.2 \% \quad p$-value

0.002

DFS at

5 years $=67.8 \%$

p-value

$65.5(24-90)$

25 (62.5)

$80.00 \%$

Location

15 (37.5)

$46.67 \%$

$80.00 \%$

\section{Left breast}

19 (47.5)

Right breast

$21(52.5)$

Histology

33 (82.5)

Ductal

7 (17.5)

Others

Grade

7 (17.5)

1

1

$15(37.5)$

$5(12.5)$

3

$5(12.5)$

NR

In situ

$19(47.5)$

No $\quad 19$ (47.5)

Yes

9 (22.5)

NR

$12(30)$

STIL

Median (range)

$10(5-60)$

$<10 \% \quad 8(20)$

$\geq 10 \%$

8 (20)

$17(42.5)$

NR

15 (37.5)

ER

Median (range)

$90(0-100)$

$<10 \%$

$\geq 10 \%$

$6(15)$

$29(72.5)$

5 (12.5)

PgR

NR

$70(0-100)$

Median (range)

$70(0-100)$

$<10 \%$

6 (15)

30 (75)

$\geq 10 \%$

4 (10)

AR

NR

$50(0-90)$

Median (range) $\quad 50(0-90)$

$>10 \%$

$17(77.3)$

$\leq 10 \%$

5 (22.7)

$80.00 \%$

\begin{tabular}{l}
$47.37 \%$ \\
\hline $85.71 \%$
\end{tabular}

$80.00 \%$

0.036

0.197

$68.42 \%$

$90.48 \%$

0.880

$66.67 \%$

$71.43 \%$

$75.76 \%$

$100.00 \%$

0.490

$57.14 \%$

$66.67 \%$

$60.00 \%$

$85.71 \%$

$80.00 \%$

$60.00 \%$

$-$

0.763

$-$

$-$

$78.95 \%$

$63.16 \%$

$66.67 \%$

$78.95 \%$

$-$

0.435

0.435

0.224

$50.00 \%$

$87.50 \%$

$58.82 \%$

$70.59 \%$

$-$

$-$

$\begin{array}{ll}0.177 & 0.137\end{array}$

Clinical tumor size

\begin{tabular}{|lll|}
\hline & Median (range) & $4(0-18)$ \\
\hline$<4 \mathrm{~cm}$ & $14(35)$ & 71.4 \\
\hline & $>4 \mathrm{~cm}$ & $17(42.5)$ \\
\hline $\mathrm{NR}$ & $9(22.5)$ & 58.8 \\
\hline Clinical stage & & \\
\hline
\end{tabular}

$100.00 \%$
$65.52 \%$
-

$100.00 \%$

$72.41 \%$

$-$

$\begin{array}{ll}0.156 & 0.447\end{array}$

$100.00 \%$
$63.33 \%$
-

$100.00 \%$

$73.33 \%$

$-$

0.2679

\begin{tabular}{|lc|}
\hline I-II & $18(45)$ \\
\hline III-IV & $18(45)$ \\
\hline NR & $4(10)$ \\
\hline
\end{tabular}

\begin{tabular}{l}
$71.43 \%$ \\
\hline $58.82 \%$ \\
\hline-
\end{tabular}

$55.55 \%$

0.058

AR: Androgen receptor; DFS: Disease-free survival; ER: Estrogen receptor; NR: Not

\begin{tabular}{ll}
$77.78 \%$ & $88.89 \%$ \\
$50.00 \%$ & $72.22 \%$ \\
- & - \\
\hline
\end{tabular}

$0.336 \quad 0.759$


Table 1. Prognostic value of clinical-pathological features $(n=40)$ (cont.).

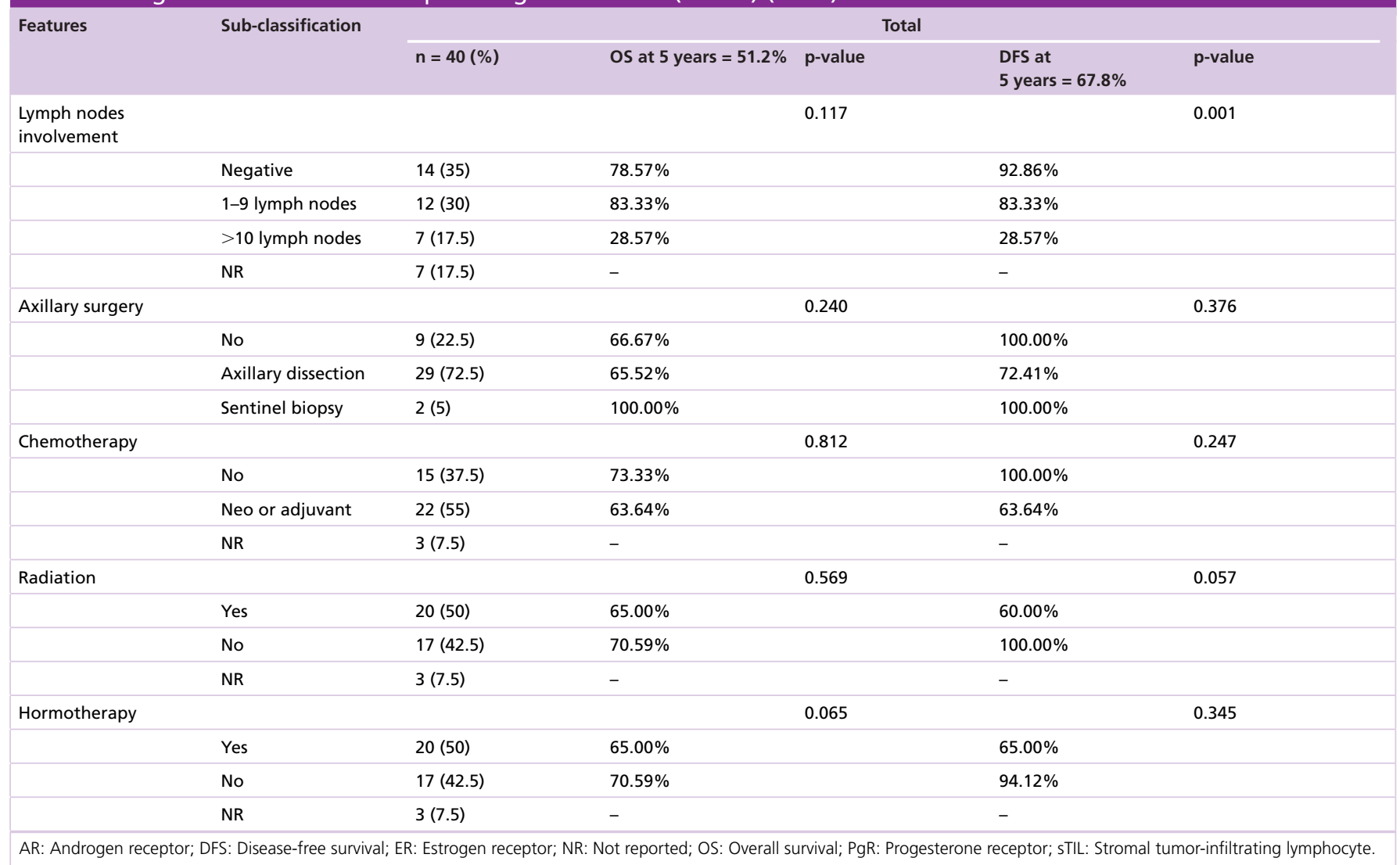

vs $\geq 10$ lymph nodes, $\mathrm{p}=0.008$ ) was associated with high DFS. Positive status of ER ( $\mathrm{n}=35, \mathrm{p}=0.177$ ) or an $\geq 10 \%$ expression of AR ( $\mathrm{n}=22, \mathrm{p}=0.267)$ was not associated to survival.

\section{Discussion}

$\mathrm{MBC}$ is a rare malignancy and its diagnosis is frequently, secondary to a metastatic lesion diagnosis [20,21]. Four of our cases presented with distant metastasis (three to bone and two to distant lymph nodes). Most frequent clinical stage in our series were II and III (40\% and 35\%, respectively). Presence of in situ disease along with invasive was found in $22.5 \%$ of our series, and is similar to the $20 \%$ reported for female series. Other variables found in our series like median age (65 years), ductal histology rate $(82.5 \%)$ and Grade II-III rate $(50 \%)$ at diagnosis were also similar to those reported in women. Analysis of survival found that older age $(\mathrm{p}=0.002)$, left-side tumor cancer location ( $p=0.036)$, clinical Stage III-IV $(p=0.058)$ have shorter survival. However, relevance of affected breast side is lost in multivariate analysis. It is similar with other series reporting an association between older age of 60 years and larger tumor with overall survival in a 400 Korean MBC series [1]. Kornegoor $e t$ al. found that high histological grade, high mitotic count and large tumor size were predictors of poor outcome in Netherlands 134 MBC cases [22]. Masci et al. found that histological grade I-II and lower ki67 were associated with shorter survival in Italian $97 \mathrm{MBC}$ cases [23]. Nilsson $e$ a al. found that higher ki67 was associated with shorter survival in a Sweden $197 \mathrm{MBC}$ series [24]. A Brazilian series with 48 male breast cancer patients found that number of compromised lymph nodes and advanced tumor, node, metastasis staging were associated with shorter survival [25].

Tumor biology of MBC remains poorly understood because it is a rare disease [26]. Most cases with available information in our series expressed ER (72.5\%) and PgR (75\%) and both were correlated with each other, however, they were not associated with survival. A previous publication found that rate of ER+in females with breast cancer who came to our Institute is much lower (59.6\%) [27]. Several series confirm that rates of hormone receptor-positive breast cancer are that higher in males than female series [13, 28-30]. Expression of ER and PgR are strongly associated with longer survival and to higher response to anti-estrogen agents in females, and some small series describe similar association in $\mathrm{MBC}[1,22]$. 
Table 2. Influence of androgen receptor status over clinicopathological features $(n=22)$.

\begin{tabular}{|c|c|c|c|}
\hline Features & Subgroups & $\mathrm{n}=22(\%)$ & $\leq 10 \%$ \\
\hline \multicolumn{4}{|l|}{ Age } \\
\hline & Median (range) & $66(24-90)$ & 67 (24-84) \\
\hline & $<70 y$ & $14(63.63)$ & 4 \\
\hline & $>70 y$ & $8(36.36)$ & 1 \\
\hline \multicolumn{4}{|l|}{ Location } \\
\hline & Left breast & $12(54.5)$ & 2 \\
\hline & Right breast & $10(45.4)$ & 3 \\
\hline \multicolumn{4}{|l|}{ Histology } \\
\hline & Ductal & $20(90.9)$ & 4 \\
\hline & Others & $2(9.1)$ & 1 \\
\hline \multicolumn{4}{|l|}{ Grade } \\
\hline & 1 & $5(22.72)$ & 2 \\
\hline & 2 & $13(59.09)$ & 2 \\
\hline & 3 & $3(13.63)$ & 1 \\
\hline & NR & $1(4.54)$ & - \\
\hline
\end{tabular}

\begin{tabular}{|lllll|}
\hline In situ & & & & \\
\hline No & $12(54.54)$ & 4 & 8 \\
\hline Yes & $9(40.9)$ & 1 & 8 \\
\hline NR & $1(4.54)$ & - & - \\
\hline
\end{tabular}

STIL

\begin{tabular}{|c|c|c|c|c|}
\hline & Median (range) & $10(5-60)$ & $10(5-20)$ & $10(5-60)$ \\
\hline & $<10 \%$ & $6(27.2)$ & 2 & 4 \\
\hline & $\geq 10 \%$ & $16(72.7)$ & 3 & 13 \\
\hline
\end{tabular}

ER

\begin{tabular}{|c|c|c|c|}
\hline & Median (range) & $10(5-60)$ & $10(5-20)$ \\
\hline & $<10 \%$ & $6(27.2)$ & 2 \\
\hline & $\geq 10 \%$ & $16(72.7)$ & 3 \\
\hline
\end{tabular}

$>10 \%$

p-value

0.612

65 (46-90)

10

7

10
7

0.624

10

16

1

$\begin{array}{ll} & \text { No value } \\ 3 & \\ 11 & \\ 2 & \\ - & 0.338\end{array}$

$\begin{array}{ll}8 & \\ 8 & \\ - & 0.585\end{array}$

\begin{tabular}{|c|c|c|c|c|c|}
\hline & Median (range) & $80(0-100)$ & $80(0-90)$ & $90(60-100)$ & \\
\hline & $<10 \%$ & $2(9.1)$ & 2 & 0 & \\
\hline & $\geq 10 \%$ & $20(90.9)$ & 3 & 17 & \\
\hline \multirow[t]{4}{*}{ PgR } & & & & & 0.043 \\
\hline & Median (range) & $82.5(0-100)$ & $90(0-90)$ & $80(10-100)$ & \\
\hline & $<10 \%$ & $2(9)$ & 2 & 0 & \\
\hline & $\geq 10 \%$ & $20(90.9)$ & 3 & 17 & \\
\hline \multirow[t]{5}{*}{ Clinical tumor size } & & & & & 0.032 \\
\hline & Median (range) & $3.5(1-18)$ & $5(4-9)$ & $3(1-18)$ & \\
\hline & $<4 \mathrm{~cm}$ & $10(45.45)$ & 0 & 10 & \\
\hline & $>4 \mathrm{~cm}$ & $10(45.45)$ & 5 & 5 & \\
\hline & NR & $2(9.09)$ & - & - & \\
\hline \multirow[t]{3}{*}{ Clinical stage } & & & & & 1 \\
\hline & $I-I I$ & $13(59.1)$ & 3 & 10 & \\
\hline & III-IV & $9(40.9)$ & 2 & 7 & \\
\hline \multirow[t]{5}{*}{ Lymph nodes involvement } & & & & & No value \\
\hline & Negative & $6(27.27)$ & 2 & 4 & \\
\hline & 1-9 lymph nodes & $10(45.45)$ & 2 & 8 & \\
\hline & $>10$ lymph nodes & $4(18.18)$ & 1 & 3 & \\
\hline & NR & $2(9.09)$ & - & - & \\
\hline
\end{tabular}

AR: Androgen receptor; DFS: Disease-free survival; ER: Estrogen receptor; NR: Not reported; OS: Overall survival; PgR: Progesterone receptor; sTIL: Stromal tumor-infiltrating lymphocyte. 

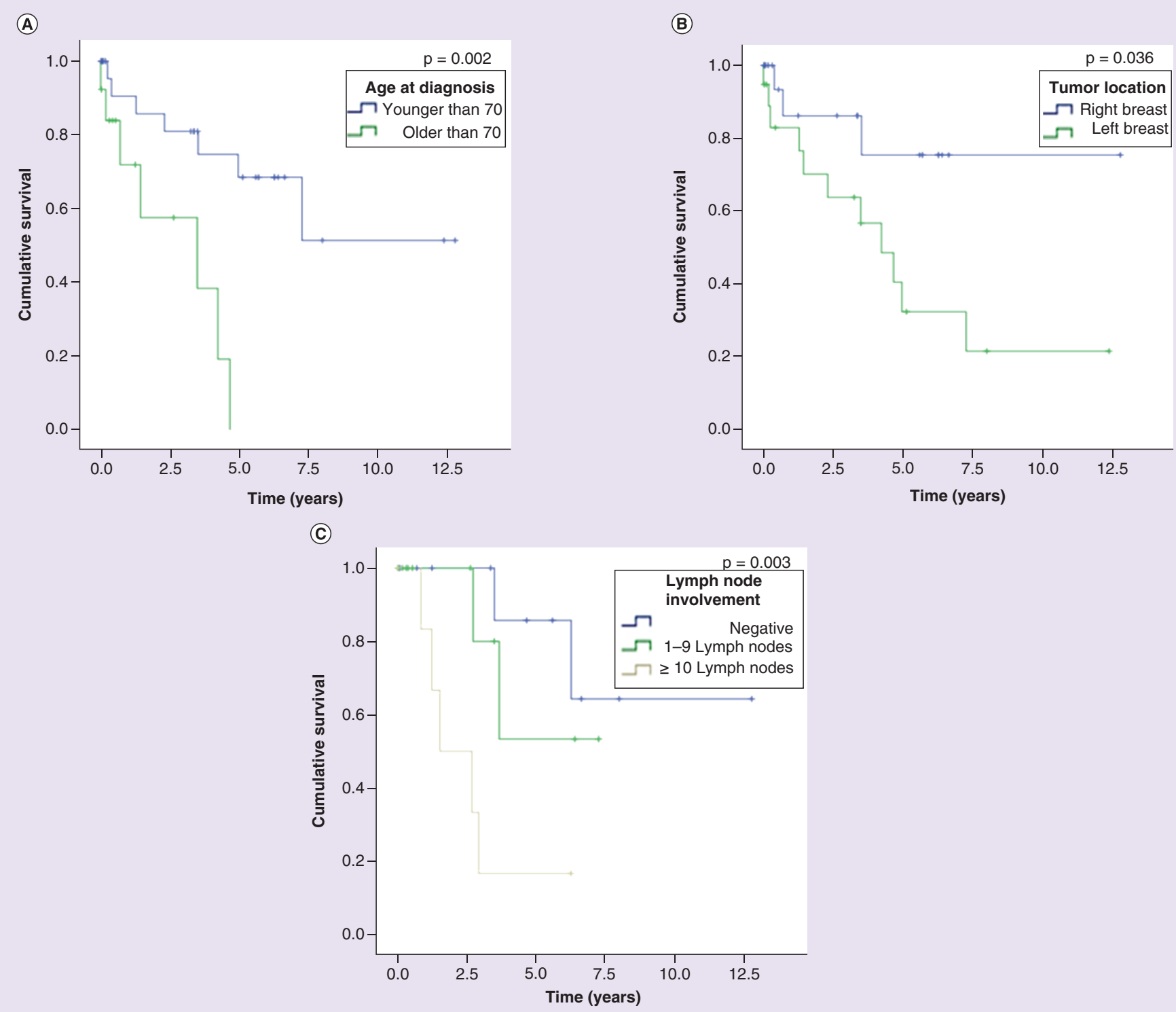

Figure 4. Clinicopathological features associated with survival. OS associated with (A) age at diagnosis and (B) tumor location. (C) DFS for the population with $\geq 10$ positive lymph nodes (yellow line), 1-9 positive lymph nodes (green line) and negative lymph nodes (blue line) are shown.

HER2 overexpression has been described as less frequent than in female series, but it is expected to behave as prognostic and predictive to anti-HER2 therapies factor $[1,31,32]$.

The greater than $10 \% \mathrm{AR}$ expression was found in $77.3 \%$ of our $\mathrm{MBC}$ cases which is in the previously described range (40-90\%), and our analyses found that AR and ER expressions were related $(p=0.043)$ which has also been previously reported (however, no previous study in South American population). However, the evaluation of the expression of AR and ER in similar tumor areas of 22 cases found, for the first time to our knowledge, that although most cells co-expressed both receptors, there is around $15 \%$ of tumor cells which express only one receptor [10-15].

There was not a relationship between AR expression and survival in our series, although it could be because of the small sample size. Previous studies have reported contradictory results about the prognostic value of AR expression. Elebro et al. evaluated AR expression in 671 women with breast cancer and found positive staining in $85 \%$ and its relationship with longer survival. They also found that having both AR and ER expression was associated with longer DFS ( $\mathrm{p}=0.002)$ [10]. Humphries et al. evaluated different IHC markers including ER and 
$\mathrm{AR}$ in $446 \mathrm{MBC}$, and found $\mathrm{ER}+$ in $84 \%$ and $\mathrm{PgR}+$ in $74 \%$. AR+ was also associated with longer DFS in the whole cohort $(\mathrm{p}=0.009)$ and in the ER+ cases $(\mathrm{p}=0.033) \mathrm{MBC}$ [13]. Shaaban et al. compared AR expression between 251 male and 263 female breast cancers. They found expression in $64 \%$ of males and $93 \%$ of females $(\mathrm{p}<0.0001)$. ER+ and AR+MBC had significantly improved OS over ER+ and AR-MBC cases $(\mathrm{p}=0.04)$ and over equivalent $\mathrm{ER}+$ and $\mathrm{AR}+$ female breast cancer $(\mathrm{p}=0.05)$ [15].

Contrary to these results, Wenhui et al. evaluated $102 \mathrm{MBC}$ and found that AR+ was associated with lymph node metastases $(p=0.032)$, shorter overall survival $(p=0.045)$ and DFS $(p=0.026)$ [14]. Similarly, Song et al. evaluated AR expression in $81 \mathrm{MBC}$ and found that it was associated with shorter survival $(\mathrm{p}=0.029)$ [12].

Despite the small size of this South American series, it reports similar clinicopathological features associated to MBC than other larger series in the Caucasian population. A remarkable strength of our study is the prospective evaluation of $\mathrm{AR}$ and $\mathrm{ER}$ in the same tumor regions by an objective and replicable digital analysis in order to evaluate the cell co-expression of receptors.

\section{Conclusion}

We can conclude that clinical stage can also predict prognosis in MBC. Expression of ER happens in most MBC cases but its relationship with survival is not clear. Most malignant cells who express AR have co-expression of ER expression; however, there are a few cases with poor correlation. Because some studies describe activity of anti-androgen drugs in AR-positive breast cancer $[4,5,8]$, we expect that more active anti-androgen drugs will be developed in the coming future and will be tested in males with cancer, and AR staining will demonstrate to be predictive for response. Therefore, we expect that anti-androgen treatment will be incorporated in the future management of breast cancer happening in males.

Summary points

- Male breast cancer (MBC) is an infrequent disease.

- Advanced clinical stage and age behaves as prognostic features in MBC.

- Prognostic role of tumor infiltrating lymphocytes in $M B C$ is not clear.

- Rate of ER+ (estrogen receptor) is highly prevalent in MBC.

- AR expression is co-related to ER expression in most cases.

- Prognostic role of ER and AR in MBC is not clear.

\section{Acknowledgements}

The authors are thankful to the use of the Automatic Multispectral Imaging System (Olympus BX63) financed by the Programa Nacional de Innovación para la Competitividad y Productividad (Innovate Peru), under the contract 317-PNICP-EC-2014.

Financial \& competing interests disclosure

The authors have no relevant affiliations or financial involvement with any organization or entity with a financial interest in or financial conflict with the subject matter or materials discussed in the manuscript. This includes employment, consultancies, honoraria, stock ownership or options, expert testimony, grants or patents received or pending, or royalties.

No writing assistance was utilized in the production of this manuscript.

\section{Ethical conduct of research}

This study was reviewed and approved by the Instituto Nacional de Enfermedades Neoplasicas Institutional Review Board. Personal and filiation data including identity of every patient was protected with an added code in the excel table. It is a retrospective case series that does not have any not activity or contact with the patients. Patients were not required to give informed consent to the study because the analysis used anonymous clinical data that were obtained after each patient agreed to treatment by written consent.

\section{Open Access}

This work is licensed under the Creative Commons Attribution 4.0 License. To view a copy of this license, visit http://creativecommons.org/licenses/by/4.0/. 


\section{References}

Papers of special note have been highlighted as: $\bullet \bullet$ of considerable interest

1. Choi M-Y, Lee SK, Lee JE et al. Characterization of Korean male breast cancer using an online nationwide breast-cancer database: matched-pair analysis of patients with female breast cancer. Medicine 95(16), 3299 (2016).

-. Large retrospective Korean series $(n=400)$ of male breast cancer $(\mathrm{MBC})$ and controls in females that find similar prognosis.

2. Hu R, Dawood S, Holmes MD et al. Androgen receptor expression and breast cancer survival in postmenopausal women. Clin. Cancer Res. 17(7), 1867-1874 (2011).

3. Labrie F, Luu-The V, Labrie $\mathrm{C}$ et al. Endocrine and intracrine sources of androgens in women: inhibition of breast cancer and other roles of androgens and their precursor dehydroepiandrosterone. Endocr. Rev. 24(2), 152-182 (2003).

4. Macedo LF, Guo Z, Tilghman SL, Sabnis GJ, Qiu Y, Brodie A. Role of androgens on MCF-7 breast cancer cell growth and on the inhibitory effect of letrozole. Cancer Res. 66(15), 7775-7782 (2006).

5. Di Monaco M, Brignardello E, Leonardi L, Gatto V, Boccuzzi G. Inhibitory effect of hydroxyflutamide plus tamoxifen on oestradiol-induced growth of MCF-7 breast cancer cells. J. Cancer Res. Clin. Oncol. 121(12), 710-714 (1995).

6. Bieche I, Parfait B, Tozlu S, Lidereau R, Vidaud M. Quantitation of androgen receptor gene expression in sporadic breast tumors by real-time RT-PCR: evidence that MYC is an AR-regulated gene. Carcinogenesis 22(9), 1521-1526 (2001).

7. Khalkhali-Ellis Z, Christian AL, Kirschmann DA et al. Regulating the tumor suppressor gene maspin in breast cancer cells: a potential mechanism for the anticancer properties of tamoxifen. Clin. Cancer Res. 10(2), 449-454 (2004).

8. Zhao TP, He GF. A Phase II clinical trial of flutamide in the treatment of advanced breast cancer. Tumori 74(1), 53-56 (1988).

9. Gucalp A, Isakoff SM, Isakoff SJ et al. Targeting the androgen receptor in women with AR+ ER-/PR- metastatic breast cancer TBCRC011. Presented at: ASCO Meeting 2012. J. Clin. Oncol. 15, 1006 (2012).

10. Elebro K, Bendahl PO, Jernstrom H, Borgquist S. Androgen receptor expression and breast cancer mortality in a population-based prospective cohort. Breast Cancer Res. Treat. 165(3), 645-657 (2017).

11. Kim Y, Jae E, Yoon M. Influence of androgen receptor expression on the survival outcomes in breast cancer: a meta-analysis. J. Breast Cancer 18(2), 134-142 (2015).

12. Song YN, Geng JS, Liu T et al. Long CAG repeat sequence and protein expression of androgen receptor considered as prognostic indicators in male breast carcinoma. PLoS ONE 7(12), e52271 (2012).

13. Humphries MP, Sundara Rajan S, Honarpisheh $\mathrm{H}$ et al. Characterisation of male breast cancer: a descriptive biomarker study from a large patient series. Sci. Rep. 7(45293), 1-9 (2017).

-• Evaluation of prognostic role of different clinicopathological features including androgen receptor (AR) in $446 \mathrm{MBCs}, 272$ that find that endrogen receptor and AR positive had the longer survival.

14. Wenhui Z, Shuo L, Dabei T et al. Androgen receptor expression in male breast cancer predicts inferior outcome and poor response to tamoxifen treatment. Eur. J. Endocrinol. 171(4), 527-533 (2014).

15. Shaaban AM, Ball GR, Brannan RA et al. A comparative biomarker study of 514 matched cases of male and female breast cancer reveals gender-specific biological differences. Breast Cancer Res. Treat. 133(3), 949-958 (2012).

-. Comparison of expression of AR in 251 male and 263 female breast cancers find a prognostic 288 role of AR expression in males with breast cancer.

16. Mottet N, De Santis M, Briers E et al. Updated guidelines for metastatic hormone-sensitive prostate cancer: abiraterone acetate combined with castration is another standard. Eur. Urol. 73(3), 316-321 (2017).

17. World Health Organization. Pathology and genetics: tumours of the breast and female genital organs. Tavassoli FA, Devilee P (Eds). IARC Press, Lyon, France (2003). www.iarc.fr/en/publications/pdfs-online/pat-gen/bb4/BB4.pdf

18. Salgado R, Denkert C, Demaria $\mathrm{S}$ et al. The evaluation of tumor-infiltrating lymphocytes in breast cancer: recommendations by an International TILs Working Group 2014. Ann. Oncol. 26(2), 259-271 (2015).

19. Hammond ME, Hayes DF, Dowsett M et al. American Society of Clinical Oncology/College of American Pathologists guideline recommendations for immunohistochemical testing of estrogen and progesterone receptors in breast cancer (unabridged version). Arch. Pathol. Lab. Med. 134(7), 48-72 (2010).

20. Ribeiro G. Male breast carcinoma: a review of 301 cases from the Christie Hospital and Holt Radium Institute, Manchester. $B r$. J. Cancer 51(1), 115-119 (1985).

21. Kidwai N, Gong Y, Sun X et al. Expression of androgen receptor and prostate-specific antigen in male breast carcinoma. Breast Cancer Res. 6(1), 18-23 (2004).

22. Kornegoor R, Verschuur-Maes AH, Buerger $\mathrm{H}$ et al. Immunophenotyping of male breast cancer. Histopathology 61(6), 1145-1155 (2012).

-• Evaluation of prognostic role of the expression of different proteins including AR in $252 \mathrm{MBC}$ : series of 134.

23. Masci G, Caruso M, Caruso F et al. Clinicopathological and immunohistochemical characteristics in male breast cancer: a retrospective case series. Oncologist 20(6), 586-592 (2015). 
24. Nilsson C, Koliadi A, Johansson I et al. High proliferation is associated with inferior outcome in male breast cancer patients. Mod. Pathol. 26(1), 87-94 (2013).

25. Mourao Netto M, Logullo A, Nonogaki S, Brentani R, Brentani M. Expression of c-erbB-2, p53 and c-myc proteins in male breast carcinoma: comparison with traditional prognostic factors and survival. Braz. J. Med. Biol. Res. 34(7), 887-894 (2001).

26. Abreu MH, Afonso N, Abreu PH et al. Male breast cancer: looking for better prognostic subgroups. Breast 26, 18-24 (2016).

27. Vallejos CS, Gomez HL, Cruz WR et al. Breast cancer classification according to immunohistochemistry markers: subtypes and association with clinicopathologic variables in a Peruvian hospital database. Clin. Breast Cancer 10(4), 294-300 (2010).

28. Dimitrov NV, Colucci P, Nagpal S. Some aspects of the endocrine profile and management of hormone-dependent male breast cancer. Oncologist 12(7), 798-807 (2007).

29. Murphy CE, Carder PJ, Lansdown MR, Speirs V. Steroid hormone receptor expression in male breast cancer. Eur. J. Surg. Oncol. 32(1), 44-47 (2006).

30. Ruddy KJ, Winer EP. Male breast cancer: risk factors, biology, diagnosis, treatment, and survivorship. Ann. Oncol. 24(6), 1434-1443 (2013).

31. Masci G, Caruso M, Caruso F et al. Clinicopathological and immunohistochemical characteristics in male breast cancer: a retrospective case series. Oncologist 20(6), 586-592 (2015).

32. Kornegoor R, Verschuur-Maes AH, Buerger H et al. Immunophenotyping of male breast cancer. Histopathology 61(6), 1145-1155 (2012). 
